OPEN ACCESS

Edited by:

Xiaofeng Yang,

Temple University, United States

Reviewed by:

Sivareddy Kotla,

University of Texas MD Anderson

Cancer Center. United States

Yafeng $L I$,

Shanxi Provincial People's

Hospital, China

*Correspondence:

Paola Maria Faggioli

paola.faggioli@asst-ovestmi.it

Antonino Mazzone

antonino.mazzone@asst-ovestmi.it

Nicola Mumoli

nicola.mumoli@asst-ovestmi.it

Specialty section:

This article was submitted to

General Cardiovascular Medicine,

a section of the journal

Frontiers in Cardiovascular Medicine

Received: 04 January 2021

Accepted: 02 March 2021

Published: 23 April 2021

Citation:

Faggioli PM, Mumoli N and Mazzone A (2021) lloprost in COVID-19: The Rationale of Therapeutic Benefit. Front. Cardiovasc. Med. 8:649499. doi: 10.3389/fCvm.2021.649499

\section{Iloprost in COVID-19: The Rationale of Therapeutic Benefit}

\author{
Paola Maria Faggioli ${ }^{1 *}$, Nicola Mumoli ${ }^{2 *}$ and Antonino Mazzone ${ }^{1 *}$ \\ ${ }^{1}$ Internal Medicine Azienda Socio Sanitaria Territoriale OVEST Milanese, Legnano Hospital, Milan, Italy, ${ }^{2}$ Internal Medicine \\ Azienda Socio Sanitaria Territoriale OVEST Milanese, Magenta Hospital, Milan, Italy
}

Keywords: COVID-19, iloprost, therapy, thrombosis, inflammation

\section{INTRODUCTION}

Recently Moezinia et al. (1) reported a beneficial effect of iloprost in the treatment of acute digital peripheral ischemia that occurred in three patients affected by acute SARS-CoV2 COVID-19 infection, and Johansson et al. (2) reported a benefit of iloprost infusion in ventilated COVID19 patients.

In both these series, iloprost was infused for five continuous days at the dose of $0.5 \mathrm{mg} / \mathrm{kg} / \mathrm{min}$, with a clinical improvement in digital ischemia and respiratory parameters.

Iloprost is a synthetic prostacyclin receptor agonist, used in the treatment of pulmonary arterial hypertension (inhalation), acute and chronic peripheral vascular disease (intravenous) such as critical ischemia, arterial obliterans diseases, digital ulcers, and severe digital ischemia in systemic sclerosis (3-5). Many reports confirm the antithrombotic, anti-inflammatory, and antifibrotic effects of iloprost and highlight its indications not only in the treatment of peripheral vascular diseases but also in critical patients without serious adverse reaction occurence (6).

\section{POSSIBLE MECHANISM OF ACTION OF ILOPROST IN COVID-19 INFECTION}

We would like to highlight the mechanisms of action of iloprost in order to clarify its role in inflammation, vasculitis, and thromboembolism in SARS-CoV2 COVID-19 infection. This is because, in agreement with numerous recent studies - also published by our own group $(7,8)$ SARS-CoV2 disease showed a clinical and pathophysiological picture very similar to inflammatory diseases with multi systemic involvement and organ damage similar to vasculitis and also similar to microangiopathic and thrombotic damage created by a pro-angiogenic microenvironment $(7,8)$. It is known that inflammatory storm, by release of cytokines (in particular IL-6), leads to an increased number of circulating activated monocytes/macrophages with the overexpression of adhesion molecules such as integrin complex. The development of cytokine storm induces extensive lung damage in which cells of the inflammatory cascade play a fundamental role as known in viral and bacterial infections. Previous reports supposed that virus such as HIV and SARS-CoV2 can induce variations of serum levels of biomarkers of endothelial damage such as intercellular adhesion molecule 1 (ICAM-1), vascular cell adhesion molecule 1 (VCAM-1), and Eselectin (9). It is also well-known that in COVID-19 infection, serum levels of fractalkine, VCAM-1, ICAM-1, and vascular adhesion protein-1 (VAP-1) were elevated in patients with mild disease, dramatically elevated in severe cases, and decreased in the convalescence phase in correlation with disease course (10-12). 


\begin{tabular}{|c|c|}
\hline Leukocyte integrins & Subunits Names Ligands \\
\hline $\begin{array}{ll}\text { aLb2 } & \text { LFA-1 } \\
\text { (CD11a/CD18) } & \\
\end{array}$ & ICAM-1, ICAM-2, ICAM-3 \\
\hline $\begin{array}{ll}\text { aMb2 Mac-1 } \\
(\mathrm{CD} 11 \mathrm{~b} / \mathrm{CD} 18)\end{array}$ & $\begin{array}{l}\text { ICAM-1, iC3b, Factor } X \text {, } \\
\text { LPS }\end{array}$ \\
\hline $\begin{array}{l}\mathrm{aXb2} \quad \mathrm{p} 150, \\
(\mathrm{CD} 11 \mathrm{c} / \mathrm{CD} 18)\end{array}$ & iC3b, Fibrinogen \\
\hline
\end{tabular}

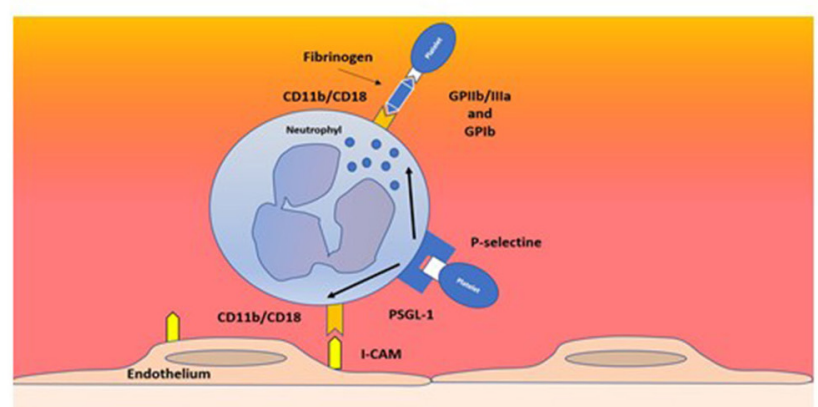

FIGURE 1 | Families of adhesion receptors and their counter receptors. CD11b/CD18 expressed on activated neutrophils supports the interaction between platelets GPIIB/IIIA and GPIb (via fibrinogen) and with endothelium via ICAM1.

\section{DISCUSSION}

Iloprost, a synthetic prostacyclin analog with potent antiaggregating and vasodilatory properties, has multiple pharmacological activities such as inhibition of platelet aggregation and leukocyte activation, down-regulation of adhesion molecule expression, improvement of endothelial function, and modulation of the inflammatory status related to systemic atherosclerotic processes (9).

Previous observations documented that CD11b/CD18, a surface receptor expressed in cellular inflammatory responses by neutrophils and activated monocytes macrophages $(8,9)$, can promote their adhesion to endothelial lining and binding soluble clotting factor $\mathrm{X}$ and that fibrinogen acts as a trigger of coagulation cascade and thrombosis, similar to what is reported in ischemic diseases. Also, interleukin-6 (IL-6) can enhance the expression of CD11/CD18 and promote the adhesion of inflammatory monocytes to endothelium mediated by ICAM and their interaction with platelets that could promote a prothrombotic state $(8-10)$.

In effect, inflammation and thrombotic events are frequently observed in the lungs of patients affected by COVID-19 as reported by Ackermann et al. (10) with a prevalence of thrombotic microangiopathy, severe endothelial damage, and intussusceptive neoangiogenesis (8-10).

Furthermore, iloprost is active in the modulation of every mechanism involved in inflammatory response and in systemic damage (8). Although not conclusive, these data seem to confirm the use of iloprost as an additional, safe, and effective therapeutic alternative that deserves to be systematically considered in patients affected by COVID-19.

Neutrophils and monocytes/macrophages actively participate in thrombosis and hemostasis cascade, but their role has not yet been sufficiently explored in COVID-19 infection. In COVID-19 pneumonia, persistent activation of circulating neutrophils and monocytes/macrophages, induced by the release of cytokines, in addition to IL-6, has been recently hypothesized (11). Previous observations documented that inflammation mediated by phagocytes in rat lungs is blocked by preincubation with anti-Mol monoclonal antibodies (heterodimeric glycoproteins expressed on the plasma membrane of neutrophils, monocytes, macrophages, and a subset of large granular lymphoid cells) preventing pulmonary injury. These antibodies react with CD11b/CD18 integrin complex, which represents a major adhesion molecular structure on neutrophils and monocytes/macrophages. In order to clarify our assumption, we report the ligands of CD11/CD18 integrin complex with molecular adhesion target in Figure 1 and the interaction between CD11b/CD18 expressed on activated neutrophil platelets and endothelium borrowed from our previous papers (12-15) (Figure 1).

It is also well known that iloprost and other synthetic prostanoids have effect in vivo and in vitro in reducing PMN adhesion; in modulating the surface expression of ICAM-1, VCAM-1, and E-selectin in inflammatory endothelial cells (13); as well as in modulating the expression of CD11b/CD18 in activated macrophages.

Therefore, it can be hypothesized that the therapeutic effects of iloprost in the treatment of vasculopathy induced by COVID19 can be explained in the modulation of the expression of adhesion molecules and of the interaction between macrophages and activated endothelium.

In support of this hypothesis, in our previous report, we reported a decrease in the serum levels of adhesion molecules, in the expression of CD11b/CD18 in correlation with the trend of COVID-19 infection $(6,14)$ and related clinical findings.

However, larger studies are needed to confirm these encouraging data observed in this small case series.

\section{AUTHOR CONTRIBUTIONS}

All authors listed have made substantial, direct and intellectual contribution to the work, and approved it for publication. 


\section{REFERENCES}

1. Moezinia C, Ji-Xu A, Azari A, Horlick S, Denton C, Stratton R. Iloprost for COVID-19 related vasculopathy. Lancet Rheumatol. (2020) 2:e5823. doi: 10.1016/S2665-9913(20)30232-0

2. Johansson PI, Bestle M, Søe-Jensen P, Kristiansen KT, Stensballe J, Clausen $\mathrm{NE}$, et al. The effect of prostacyclin (Iloprost) infusion at a dose of 1 $\mathrm{ng} / \mathrm{kg} / \mathrm{min}$ for 72 hours compared to placebo in mechanically ventilated patients with COVID-19: A structured summary of a study protocol for a randomized controlled trial. Trials. (2020) 21:746. doi: 10.1186/s13063-020-0 4696-2

3. Olschewski H, Simonneau G, Galiè N, Higenbottam T, Naeije R, Rubin LJ, et al. Inhaled iloprost for severe pulmonary hypertension. N Engl J Med. (2002) 347:322-29. doi: 10.1056/NEJMoa020204

4. Hughes M, Ong VN, Anderson ME, Hall F, Moinzadeh P, Griffiths B. Consensus best practice pathway of the UK scleroderma study group: digital vasculopathy in systemic sclerosis. Rheumatology. (2015) 54:201524. doi: 10.1093/rheumatology/kev201

5. Stratton R, Shiwen X, Martini G, Holmes A, Leask A, Haberberger T, et al. Iloprost suppresses connective tissue growth factor production in fibroblasts and in the skin of scleroderma patients. J Clin Invest. (2001) 108:2415. doi: 10.1172/JCI12020

6. Meini S, Dentali F, Melillo ED, De Donato G, Mumoli N, Mazzone A, et al. Prostanoids for critical limb ischemia: a clinical review and consideration of current guideline recommendations. Angiology. (2020) 71:226-34. doi: 10.1177/00033197198 89273

7. Castelnovo L, Capelli F, Tamburello A, Faggioli P, Mazzone A. Symmetric cutaneous vasculitis in COVID-19 pneumonia. J Eur Acad Dermatol Venereol. (2020) 34:e362-3. doi: 10.1111/jdv.16589

8. Mazzone A, Castelnovo L, Tamburello A, Gatti A, Brando B, Faggioli P, et al. Monocytes could be a bridge from inflammation to thrombosis on COVID-19 injury: a case report. Thrombosis. (2020). 1:100007 doi: 10.1016/j.tru.2020.100007
9. Tong M, Jiang YD, Xiong Y, Zheng Q, Chen F. Elevated expression of serum endothelial cell adhesion molecules in COVID-19 patients. J Infect Dis. (2020) 222:894-8. doi: 10.1093/infdis/jiaa349

10. Ackermann M, Verleden SE, Kuehnel M, Haverich A, Welte T, Laengeret F, et al. Pulmonary vascular endothelitis, thrombosis, and angiogenesis in Covid19. N Engl J Med. (2020) 383:120-2. doi: 10.1056/NEJMoa2015432

11. Meini S, Giani T, Tascini C. Intussusceptive angiogenesis in Covid-19: hypothesis on the significance and focus on the possible role of FGF2. Mol Biol Rep. (2020) 47:8301-4. doi: 10.1007/s11033-020-05831-7

12. Mazzone A, De Servi S, Ricevuti G, Mazzucchelli I, Fossati G, Pasotti $\mathrm{D}$, et al. Increased expression of neutrophil and monocyte adhesion molecules in unstable coronary artery disease. Circulation. (1993) 88:35863. doi: $10.1161 / 01 . C I R \cdot 88.2 .358$

13. Mazzone A, Ricevuti G. Leukocyte CD11/CD18 integrins: biological and clinical relevance. Haematologica. (1995) 80:161-75.

14. Gatti A, Radrizzani D, Viganò P, Mazzone A, Brando B. Decrease of nonclassical and intermediate monocyte subsets in severe acute SARS-CoV-2 infection. Cytometry A. (2020) 97:887-90. doi: 10.1002/cyto.a.24188

15. Falanga A, Marchetti M, Barbui T, Smith CW. Pathogenesis of thrombosis in essential thrombocythemia and polycythemia vera: the role of neutrophils. Sem Hematol. (2005) 42:239-47. doi: 10.1053/j.seminhematol.2005. 05.023

Conflict of Interest: The authors declare that the research was conducted in the absence of any commercial or financial relationships that could be construed as a potential conflict of interest.

Copyright (c) 2021 Faggioli, Mumoli and Mazzone. This is an open-access article distributed under the terms of the Creative Commons Attribution License (CC BY). The use, distribution or reproduction in other forums is permitted, provided the original author(s) and the copyright owner(s) are credited and that the original publication in this journal is cited, in accordance with accepted academic practice. No use, distribution or reproduction is permitted which does not comply with these terms. 